\title{
Effect of Cross-Ventilation and Solar Irradiation on IAQ as a function of Roof Angle
}

\author{
Anil B. Atalar, ${ }^{1, *}$, Murat Cakan ${ }^{2}$ \\ ${ }^{1}$ M.Sc., Department of Mechanical Engineering, Istanbul Technical University, Istanbul, 34437, Turkey \\ ${ }^{2}$ Ph.D., Department of Mechanical Engineering, Istanbul Technical University, Istanbul, 34437, Turkey
}

\begin{abstract}
Natural ventilation is the most conventional and one of the significant alternative applications for energy efficiency. Cross-ventilation is commonly used in hospitals, shopping centres or greenhouses. In this study, cross-ventilation for a greenhouse was investigated. The greenhouse buildings may differ in design depending on the region and climate. Therefore, when natural ventilation methodology is carried out in these buildings, the effect of solar radiation should also be taken into consideration. There have been many studies on natural ventilation in the literature, but while these studies have been conducted, the impact of solar irradiation has never been combined. In the present study computational geometry was created according to 4 different roof inclinations: $0^{\circ}, 15^{\circ}, 30^{\circ}$, and $45^{\circ}$ - provided that the inlet and outlet opening positions are fixed. Moreover, each inclination was simulated at the following hours of the day: 10:00, 13:00 and 16:00 in June. The hex-dominant grid was created for a computational domain using Cut-cell method and Renormalization-group (RNG) k- $\varepsilon$ turbulence model provides the best results and efficient computational cost. In addition to this, Discrete Ordinates (DO) radiation model with SIMPLE algorithm was implemented for solar radiation effect. In order to decrease the temperature of the reference line, the evaporating cooling methodology was performed and a new PVC cover material was applied. Numerical predictions show that solar irradiance combined with roof inclination and outlet opening position has a significant effect on velocity and temperature distribution inside the building space. The air mass flow rate which aspirates from outlet increases considerably when the inclination angle is increased, also flow character changes according to configurations. Evaporative cooling creates a decrease in temperatures on the reference line up to $2-2.5^{\circ} \mathrm{C}$ when compared with the reference model.
\end{abstract}

\section{Introduction}

The natural ventilation provides energy efficiency when used in the place of conventional mechanical air conditioning methods. For the natural ventilation to occur, there must be a pressure difference between the inlet and outlet and the fluid flow moves from high pressure to low pressure. In small scale buildings, winddriven cross-ventilation is used to balance fresh air distribution and it can be applied with a saw-tooth roof which performs as windcatcher because of the underpressure region behind the building, this configuration enables more air mass flow rate and more uniform and higher daylight intensity levels. The outlet, which is located in the leeward part of the building helps to extract air from indoor and there is an average gain of $22 \%$ air volume flow rate with $45^{\circ}$ roof inclination with respect to flat roof configuration [1].

In order to prevent rain entrainment over the roof and to gain more fresh air, the saw-tooth roof is used in greenhouse configurations. Also, the saw-tooth roof is suitable for cross-ventilation and has advantages for withstanding different loads and for easy assembly [2-3].
CFD analysis of a greenhouse roof model with windward and leeward openings was carried out in the literature to obtain the temperature distribution as a function of roof inclination and external wall surface area [4]. In addition, dehumidification and temperature balance study were also investigated according to opening type. Roof opening is the best choice for effective cooling in summer and for dehumidification in the winter season. Furthermore, when opening size increases, duration of dehumidification decreases exponentially [5].

In this study, wind-driven cross ventilation was investigated with solar heat flux and optimization research was carried out using evaporative cooling. Solar heat energy is converted to the form of electromagnetic rays and travels through the interplanetary system. This way, it provides heat transfer during this process, which is called radiation. Radiation heat transfer from the sun to the earth is related to different parameters such as the position of the source and the target, orbit's shape or distance between the sun and earth [6]. Polyvinyl chloride (PVC) material which has high durability and flexibility was used in this numerical study as the cover material of the greenhouse. PVC is an appropriate

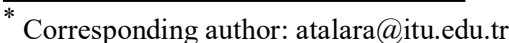


material to cast shade for plants in the greenhouse. Moreover, this material can help to reject heat and reflect long wave infrared radiation (IR) [7].

In order to decrease the average temperature in the greenhouse and to ease plant growth, evaporative cooling is used as one of the alternative methods for zero energy solution. An interior pool was utilized as a water irrigation-drainage system to maintain the conditions for proper evaporative cooling and humidification of the greenhouse space. Evaporation model can be applied in CFD simulations as water vapour mass source which spreads air-water interface [8].

There are different evaporation models in literature and one of the most accurate formulations is VDI 2089 German standards, which defines the evaporation rate in $[\mathrm{g} / \mathrm{h}]$. The formulation was corrected with evaporation coefficient which was adjusted between 5-15 for unoccupied pools [9].

In this paper, wind-driven cross ventilation combined with solar irradiation based on optimization methods for decreasing temperature was investigated. Temperature distributions within the space were graphed according to different roof inclinations. Moreover, the roles of higher absorptivity coverage material and evaporative cooling on space temperature distribution were studied for selected roof inclinations.

\section{Problem Formulation and Model Development}

The Turkish city of Antalya (36 $54^{\prime} 29.23^{\prime \prime N}$, $\left.30^{\circ} 41^{\prime} 44.02^{\prime \prime E}\right)$ which has high annual average temperatures and relative humidity is one of the most important regions for medium-large scale greenhousing and agriculture. In the summer season, greenhouses need certain shading because of temperature balance. Besides, to prevent rainwater entrainment effect, roof inclination can be considered as a solution for draining the rain. However, the roof inclination angle has also an effect on space temperature distribution according to sun's position. The average velocity of wind is taken as 3.1 $\mathrm{m} / \mathrm{s}$ from the prevailing direction of west and sun positions are affected according to 10:00, 13:00 and 16:00 hours which are presented Figure 1.

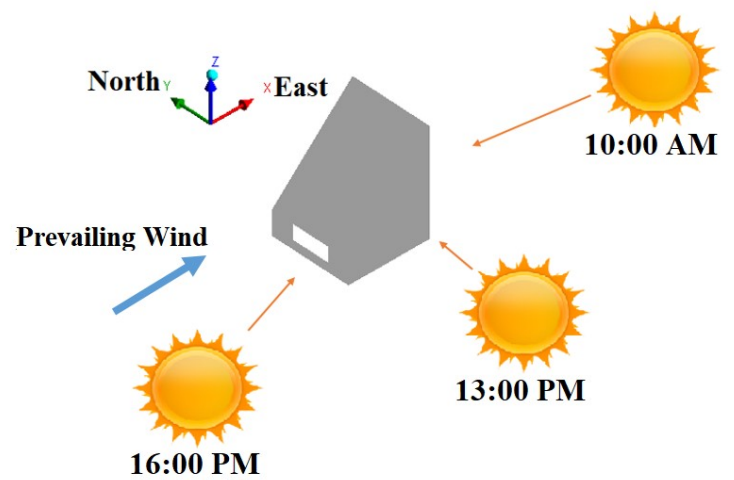

Fig. 1. Case study according to $45^{\circ}$ roof inclination.
The main parameters used in this study are roof inclination and sun's location at three distinct hours of the day. In order to obtain the highest exchange air volume rate and temperature distribution at the reference line, roof inclination is varied $15^{\circ}, 30^{\circ}$ and $45^{\circ}$ with respect to horizontal roof case $\left(0^{\circ}\right)$. Four different roof angles were considered with fixed inlet and outlet positions. While inclination is varied, outlet and inlet locations stay fixed. Figure 2 shows the variations of roof model where reference height is changing with inclination. However, the volume of the greenhouse is kept the same because of the fact that inclination reference is adjusted according to the mid-building section. Therefore; respectively volume-1, volume-2, volume- 3 , and volume- 4 denote same capacity of air.

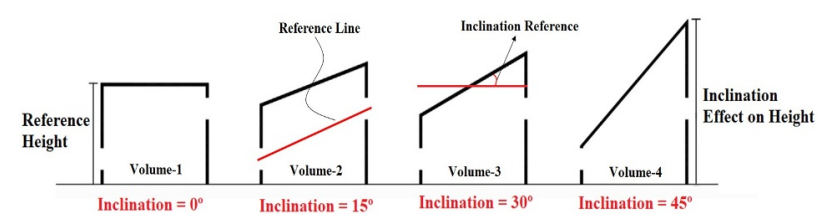

Fig. 2. Variations of inclination respectively $0^{\circ}, 15^{\circ}, 30^{\circ}, 45^{\circ}$.

In northern African countries such as Egypt, the average shading is around $30 \%$. Generally, polyvinyl chloride (PVC) is used as coverage material instead of glass. Cover PVC used in this study has $1 \mathrm{~mm}$ thickness and $0.25 \mathrm{~W} / \mathrm{mK}$ thermal conductivity. The ground material on the other hand is selected as soil which has $0.6 \mathrm{~W} / \mathrm{mK}$ thermal conductivity.

After predicting the temperature distribution on the reference line, optimum solutions have been investigated using drainage system in the middle of the building and using another PVC material, which enables higher shading effect. All simulations were carried out according to $20 \%$ absorptivity rate; however, new PVC material has $35 \%$ absorptivity in order to provide more shading effect. Thereby, different absorptivity ratios of cover material were investigated comparatively for temperature distribution. Also, approximate emissivity and absorptivity ratios were obtained according to the previous literature study [5].

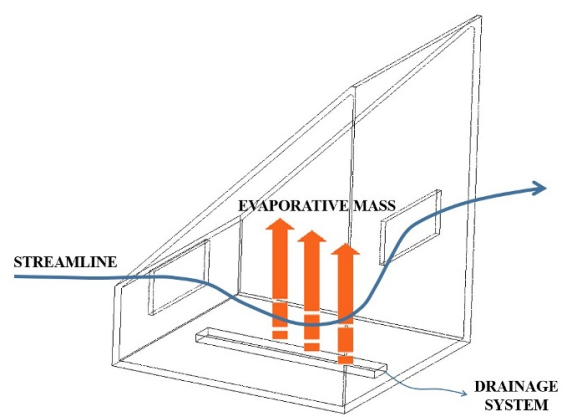

Fig. 3. Evaporative cooling system for $45^{\circ}$ roof inclination.

The water drainage system functions like a pool and it enables water evaporate from air-water interface. Figure 3 shows the location of evaporative cooling system and the pertaining method. Moreover, the width 
and length of water drainage are respectively $10 \%$ and $80 \%$ of the greenhouse depth.

\section{Outline of CFD}

Computational Fluid Dynamics is one of the best methods to obtain pre-development model. The CFD method, which reduces most of the experimental costs, easily provides the data requested by the designer with post-process facilities.

All computations and simulations were performed using ANSYS Fluent 19.0 software with a computer which has 8 core-3.6GHz processor and $16 \mathrm{~GB}$ of RAM. Approximately 5000 iterations were accomplished for each simulation.

\subsection{Computation Geometry and Grid}

The greenhouse model geometry dimensions are $5 \mathrm{x} 5 \mathrm{x}$ $4 \mathrm{~m}^{3}(\mathrm{~W} \times \mathrm{D} \times \mathrm{H})$. When the roof inclination is varied, the reference geometry is revised. The reference point of the inclination angle is based on the middle height of the roof and it is modified for each inclination angle $\left(0^{\circ}, 15^{\circ}, 30^{\circ}, 45^{\circ}\right)$. Although the geometry is changing, volume of the building remains the same. In addition, inlet and outlet section have same dimensions, which are $2.3 \times 0.9 \mathrm{~m}^{2}(\mathrm{~W} \times \mathrm{H})$, and their position is fixed in all cases. All dimensions and measurement plane are shown in Figure 4.

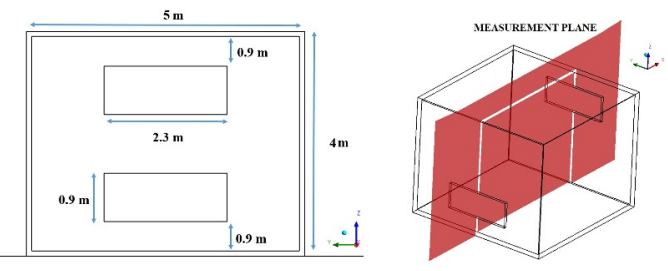

Fig. 4. Reference greenhouse dimensions

The control volume which was created for this building is shown in figure 5 where $\mathrm{H}$ represents the height of the reference building $(4 \mathrm{~m})$. The dimensions of the control volume are decided according to previous literature research.

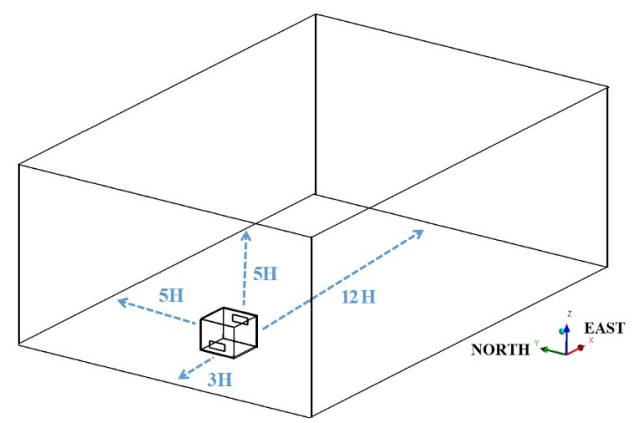

Fig. 5. Control volume dimensions

Nominally the computational grid consists of $1,820,436$ elements for reference geometry and the number of elements is changing around 1,900,000 according to roof angle. Mesh independence study was performed in Perén's research [1] and approximately $1,600,00$ elements were created for good quality mesh. After simulations, $\mathrm{y}^{+}$values were kept between 30-300 and mesh quality was considered sufficient for this case study. Cut-cell method, which is presented in figure 6, was used for creating dominant hex-mesh and minimum orthogonality is higher than 0.3 .

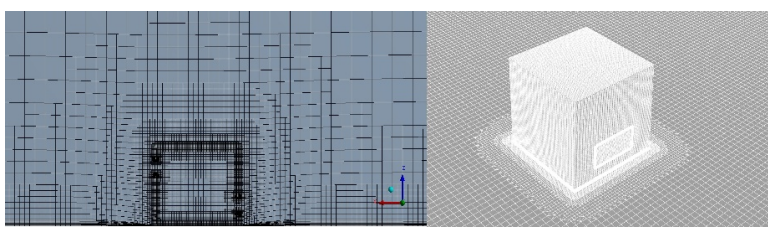

Fig. 6. Mesh structure

\subsection{Boundary Conditions}

14 different cases were tested in this study. Average wind speed and temperature are obtained respectively $3.1 \mathrm{~m} / \mathrm{s}$ and $300[\mathrm{~K}]$ for Antalya, Turkey for the month of June. Moreover, solar irradiance is applied to greenhouse walls, so temperature and velocity distributions are changed.

The sun moves from east to west; therefore, the sun's position continue to change during the day and temperature of the building increases or decreases according to roof inclination. The latitude of Antalya, Turkey is 36.55 , and the longitude is 32.00 and Fluent 19.0 is capable to calculate solar irradiation from the sun according to GPS position and reference date which is adjusted as June.

Greenhouse cover material is made of PVC, has 1 $\mathrm{mm}$ thickness and all walls are exposed to solar heat flux because of transparency. Therefore, radiation and convection boundary conditions are applied. Heat transfer coefficient is selected $25 \mathrm{~W} / \mathrm{m}^{2} \mathrm{~K}$ for freestream air and radiation B.C. type is considered as semitransparent wall. Absorptivity is initially taken respectively 0.2 but then is changed to 0.3 in the second configuration. The transmissivity value is fixed at 0.8 .

Third configuration is related to evaporative cooling model and water vapour mass is applied as species in the simulation, thus this mass source spreads from water-air interface to indoor environment. Evaporative cooling enables the relative humidity to increase and decrease the indoor temperature. In addition, evaporation rate was calculated using VDI German standards and calculated mass source was applied as mass flow inlet with $100 \%$ relative humidity. Temperature of water is obtained $298[\mathrm{~K}]$ and relative humidity of air is determined $60 \%$ for Antalya region in the month of June.

$$
E_{p}=\left[e\left(P_{w}-P_{a}\right) A\right]
$$

In VDI 2089 German standards, $E p$ is evaporation rate in $[\mathrm{g} / \mathrm{h}] ; P_{w}$ and $P_{a}$ represent respectively saturation pressure at room air dew point and saturation vapour pressure taken at surface water temperature in [mbar]. $A$ denotes pool area in $\left[\mathrm{m}^{2}\right]$. Similar with the typical activity factor in the ASHRAE's Evaporation formulation, $e$ is the evaporation coefficient of VDI 2089 
German standard which defines evaporation coefficient between 5-15 for unoccupied pools and average evaporation mass was obtained $0.0000691 \mathrm{~kg} / \mathrm{s}$. Furthermore, the most important factor of temperature and relative humidity distribution is closely related with flow streamline characteristic [8].

\subsection{Solver Settings}

Numerical computations were carried out by using Fluent software. 3D, incompressible and steady state Reynolds-Averaged Navier-Stokes (RANS) equations are solved with the help of the Renormalization-group (RNG) k- $\varepsilon$ turbulence model. In the previous study, the RNG model is reported to have more accurate results than other turbulence models [1]. The SIMPLE algorithm and second order discretization schemes are applied respectively for pressure-velocity coupling and convection-viscous terms. Convergence criteria is imposed when residuals reach $10^{-4}$ for momentum, continuity, $\mathrm{k}$ and $\varepsilon$ terms. Furthermore, radiation and thermal models are activated for all simulations and Discrete Ordinated (DO) model was used for solar heat flux calculations.

\section{Results and Discussion}

Figure 7 shows non-dimensional velocity magnitude $\left(|\mathrm{V}| / \mathrm{U}_{\text {ref }}\right)$ distribution on the measurement plane (middle of the building section). $U_{\text {ref }}$ velocity is $3.1 \mathrm{~m} / \mathrm{s}$ and as inclination increases, air mass flow rate is getting higher. Mass flow rate for $45^{\circ}$ roof inclination at the outlet section is $19 \%$ higher than that of reference geometry. Mass flow rate increases from $4.21 \mathrm{~kg} / \mathrm{s}$ to $5.02 \mathrm{~kg} / \mathrm{s}$ and fresh air circulation for greenhouse is provided using inclination because roof inclination effects low pressure region behind the building. Furthermore, nondimensional velocity magnitude has lower values at the low pressure region behind the building; however, $|\mathrm{V}| / \mathrm{U}_{\text {ref }}$ reaches up to 1.6 over the roof. The air entering from the inlet is directed towards the ground and then it rises against the opposite wall. Especially at the outlet section, this value is changing between 0.7 and 0.9 according to inclination.

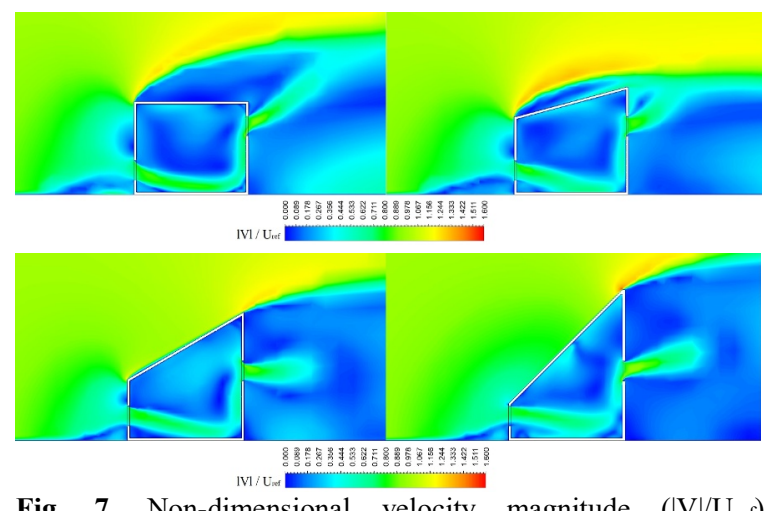

Fig. 7. Non-dimensional velocity magnitude $\left(|\mathrm{V}| / \mathrm{U}_{\text {ref }}\right)$ distribution on measurement plane
Moreover, $\left(|\mathrm{V}| / \mathrm{U}_{\text {ref }}\right)$ distribution is very similar to the PIV experimental study, which was obtained through Karava's non-dimensional velocity magnitude distribution [1].

Temperature distributions on the reference line, which extends from inlet to outlet linearly for 12 cases were obtained according to roof inclination and sun's position and denoted respectively in figure 8,9 and 10 . For example, I45-16 indicates the results obtained for $45^{\circ}$ roof inclination at 16:00 hours. Freestream has 300 $[\mathrm{K}]$ and when airflow enters the greenhouse, air is heated by solar effect and thermal accumulation. The reference line representation in graphs is symbolic for $45^{\circ}$ roof angle and each graph includes all inclination configuration at a given time.

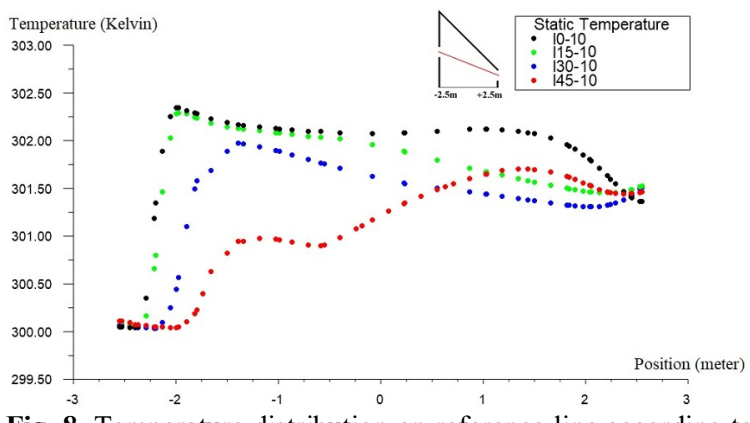

Fig. 8. Temperature distribution on reference line according to inclination at 10:00

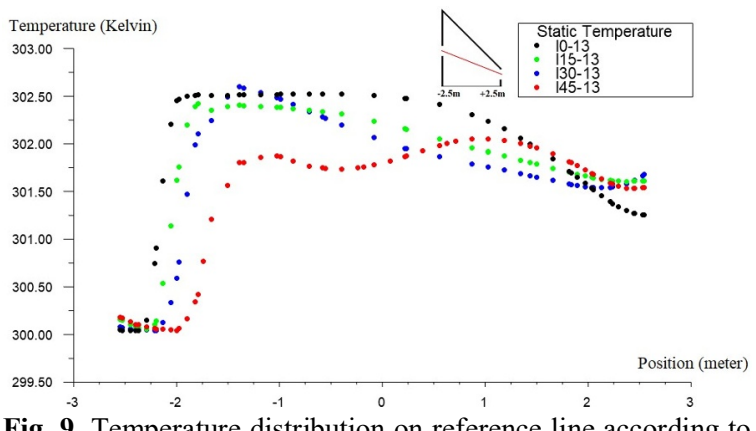

Fig. 9. Temperature distribution on reference line according to inclination at 13:00

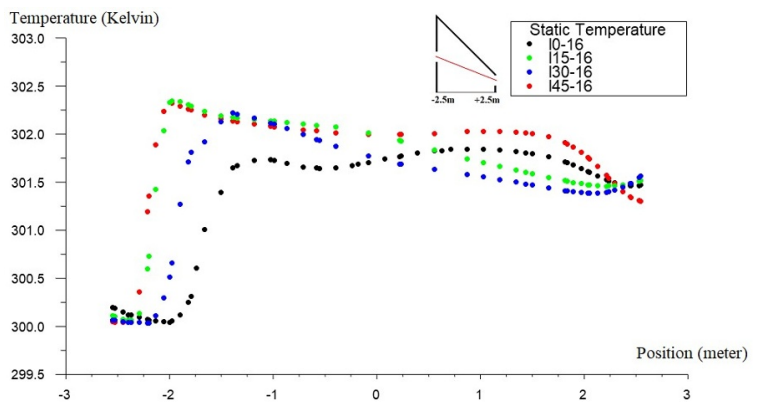

Fig. 10. Temperature distribution on reference line according to inclination at 16:00

In almost all cases, temperature increases from $27{ }^{\circ} \mathrm{C}$ to $29.5^{\circ} \mathrm{C}$ because of solar irradiance. The temperature is higher when the solar rays arrive in vertical angles. 
The maximum temperature is $29.65{ }^{\circ} \mathrm{C}$ for reference geometry at 13.00 . There is around $1-1.5{ }^{\circ} \mathrm{C}$ temperature difference between best and worst inclination configuration. Higher inclination gives advantage in early hours of the day, while it acts in the unfavourable direction when sun starts to go down.

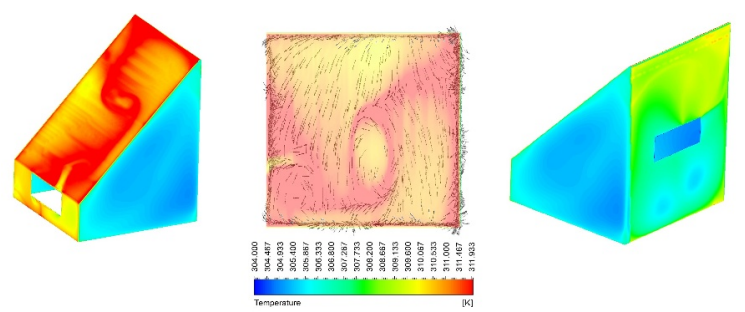

Fig. 11. Temperature distribution on PVC cover material and velocity distribution from $10 \mathrm{~cm}$ offset from cover

Temperature reaches $38^{\circ} \mathrm{C}$ on the roof and side walls remain at $32^{\circ} \mathrm{C}$ because of shading and latitude effects. In addition, there is a random temperature distribution along the $10 \mathrm{~cm}$ offset from the cover because of velocity streamlines. Figure 11 presents velocity contours on this offset and temperature distribution on PVC material. After air is aspirated from inlet opening, it goes towards the ground and hits the opposite wall. airflow transforms into swirl flow in the greenhouse. Therefore, this swirl flow affects the temperature distribution on the roof and sidewalls and makes a temperature difference of about $1-2{ }^{\circ} \mathrm{C}$ with the interior average temperature.

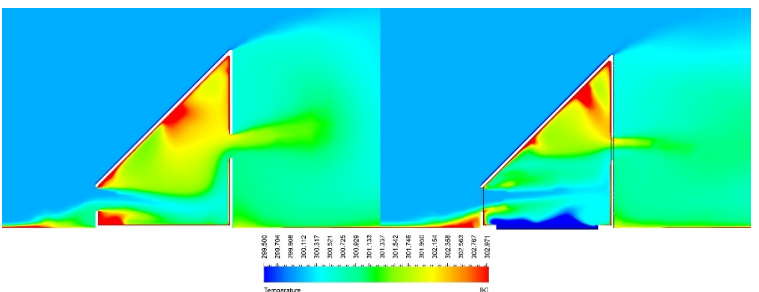

Fig. 12. Comparison of temperature distribution for reference model and evaporative cooling technique on the measurement plane at 16.00 .

In order to decrease the space temperature, alternative methods, which can be listed as using another higher absorptivity PVC material (\%35 absorptivity) and evaporative cooling using drainage or irrigation system, are considered. The reference material has 0.20 absorptivity and new PVC material can provide up to 0.35 absorptivity values. Figure 12 shows the temperature distribution on measurement plane using evaporative cooling method and water drainage system. This configuration decreases the temperature up to 1.5 meters above the ground. Freestream air has $60 \%$ relative humidity $(\mathrm{RH})$ and this value reaches an average of $76 \%$ RH using evaporative cooling in the greenhouse because of the fact that water vapour increases the mass fraction of water in the air. Water vapour mass spreads from air-water interface to indoor with $100 \% \mathrm{RH}$ and at $25^{\circ} \mathrm{C}$. Also, this humidification process enables to store vegetables as fresh as possible.

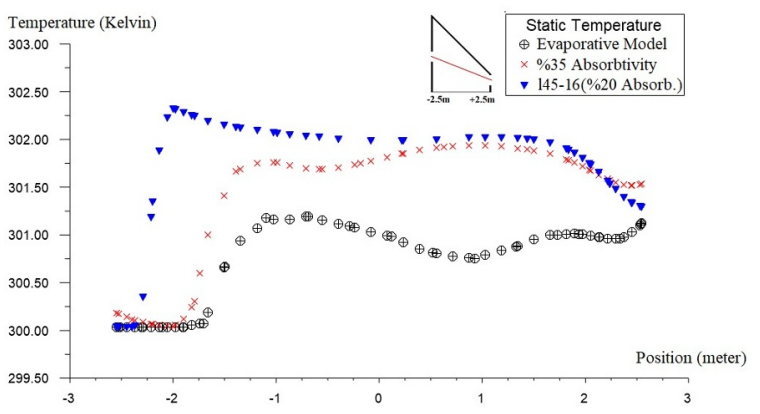

Fig. 13. Comparison of temperature distribution on reference line according to different cooling methods for $45^{\circ}$ inclination

Furthermore, there are 3 different temperature distributions which are denoted in Figure 13 that help to understand the roles of different cooling methods. There is a $1^{\circ} \mathrm{C}$ difference between 0.2 absorptivity with $45^{\circ}$ roof angle and 0.35 absorptivity with $45^{\circ}$ roof angle. However, material absorptivity could not alone provide decreasing temperatures for the regions, which are close to the walls. Moreover, evaporative cooling is able to decrease temperatures from $29.7{ }^{\circ} \mathrm{C}$ to $27.8{ }^{\circ} \mathrm{C}$. Therefore, this method can be applied to any roof inclination. In order to obtain ideal air comfort for residential applications, relative humidity should not exceed $60 \%$ according to ASHRAE Fundamental Book [10]; however, there is a totally different humidification expectation in greenhouses and most fruits and vegetables need appropriate shading and humidity within the greenhouse space.

\section{Conclusion}

This paper presents the results of numerical investigations of cross ventilation within a greenhouse according to the sun's position and roof inclination. The predictions for all inclinations were performed according to 3 sun positions at a certain time of the day. The location of Antalya was obtained as latitude and longitude wise. solar ray direction was calculated in accordance with 10:00, 13:00 and 16:00. In order to decrease indoor temperate, drainage or irrigation system of $0.1 \times 4 \mathrm{~m}^{2}$ surface area which enables evaporative cooling was used.

This study which extends in the overall to 14 different cases can be applicable for low-rise buildings as well. Because of the fact that the study takes into consideration different geometries, parameterized cutcell methods were used for all simulations and grid consists of around 1,900,00 elements. Symmetric boundary conditions could not be applied because of irradiance asymmetry.

It is observed that when the inclination is increasing, the air mass flow rate increases too. Thus, fresh air can be aspirated more from the inlet. $45^{\circ}$ Roof angle aspirates $19 \%$ more fresh air compared with $0^{\circ}$ roof 
angle reference geometry (Air mass flow rate reaches up to $5.02 \mathrm{~kg} / \mathrm{s}$ from $4.21 \mathrm{~kg} / \mathrm{s}$ ).

Also, the air which flows over the plants near the ground helps to ventilate them better. The air entering from the inlet is directed towards the ground and then it rises against the opposite wall. This circulation has a beneficial effect on temperature distribution on the roof and walls. Generally, temperature increases from $27{ }^{\circ} \mathrm{C}$ to $29.5^{\circ} \mathrm{C}$ on the reference line.

At 10:00, the highest temperature on the reference line is obtained for the $0^{\circ}$ reference geometry because inclination against the sun provides shading effect and decreases temperature. Therefore, the lowest temperature is $28^{\circ} \mathrm{C}$ and accomplished by $45^{\circ}$ inclinations.

At 13:00, the highest temperature on the reference line is obtained for the $0^{\circ}$ reference geometry too because all cases take solar ray perpendicular; thus closest roof to the reference line enables higher temperature on reference line. Also, the maximum temperature was obtained for this case with $29.65^{\circ} \mathrm{C}$.

At 16:00, the highest temperature on reference line is obtained for the $45^{\circ}$ reference geometry because the location of the sun is westward at this time and while inclination is getting higher, sunlight hits the roof perpendicularly. So that $45^{\circ}$ roof inclination has negative effect on temperature for 16:00.

In order to decrease temperature, higher absorptivity PVC material (0.35) was used and compared to lower absorptivity material (0.20). In this case, $1{ }^{\circ} \mathrm{C}$ temperature drop was revealed. Also, the temperature distribution on the PVC cover material is related to streamline character because of the fact that wind which enters from inlet hits the opposite wall and spreads indoor with swirl character. Therefore, the temperature distribution on the PVC exhibits a non-uniform distribution.

Another method is evaporative cooling using irrigation or drainage pool for decreasing temperature. Evaporation of water decreases the temperature of air with energy transfer, so indoor space can be cooled by water vapour. Evaporation mass was calculated $0.0000691 \mathrm{~kg} / \mathrm{s}$ with evaporation coefficient according to VDI 2089 German standards and it was applied to airwater interface with $25^{\circ} \mathrm{C}$. Evaporation cooling decreases temperature from $29.7^{\circ} \mathrm{C}$ to $27.6^{\circ} \mathrm{C}$.

As a result, it is possible to adjust the roof angle according to the position of the sun and the maximum solar heat flux. Thus, the greenhouse is protected from both rain and extreme temperatures. In addition, the irrigation or drainage pool can function as evaporative coolers to lower the temperature.

In future studies, the evaporative cooling effect will be investigated with the dispersed phase model and the shading effect of transparent materials will be also performed for high-rise building's windows.

\section{References}

1. J. Perén, T. V. Hooff, B. Leite, and B. Blocken, "CFD analysis of cross-ventilation of a generic isolated building with asymmetric opening positions: Impact of roof angle and opening location," Building and Environment, vol. 85, pp. 263-276 (2015)

2. D. Briassoulis, D. Waaijenberg, J. Gratraud, and B. V. Elsner, "Mechanical Properties of Covering Materials for Greenhouses Part 2: Quality Assessment," Journal of Agricultural Engineering Research, vol. 67, no. 3, pp. 171-217 (1997)

3. F. Kempkes, G.-J. Swinkels, and S. Hemming, Verbetering lichtinval winterlicht. Bleiswijk: Wageningen UR Glastuinbouw (2015)

4. H. Fatnassi, T. Boulard, C. Poncet, and M. Chave, "Optimisation of Greenhouse Insect Screening with Computational Fluid Dynamics," Biosystems Engineering, vol. 93, no. 3, pp. 301-312 (2006)

5. K.-S. He, D.-Y. Chen, L.-J. Sun, Z.-L. Liu, and Z.Y. Huang, "The effect of vent openings on the microclimate inside multi-span greenhouses during summer and winter seasons," Engineering Applications of Computational Fluid Mechanics, vol. 9, no. 1, pp. 399-410 (2015)

6. "The Climate System," Solar Radiation and the Earth's Energy Balance. [Online]. Available: https://eesc.columbia.edu/courses/ees/climate/lectur es/radiation/index.html.

7. "Greenhouse covering materials," NSW Department of Primary Industries, 12-Jun-2007. [Online]. Available:

https://www.dpi.nsw.gov.au/agriculture/horticulture/ greenhouse/structures-and-technology/covers (2007)

8. Anil B. Atalar, M. Cakan, "Analysis of Wind Catcher, Decorative Pool and Outlet Opening Combinations on Evaporative Cooling of Residential Interiors," Athens, ASHRAE Hellenic Chapter- Energy in Buildings Conference, (2018, November)

9. Technische Gebäudeausrüstung von Schwimmbädern. Berlin : Beuth (2000)

10. 1999 ASHRAE handbook: heating, ventilating, and air-conditioning applications. Atlanta, GA: American Society of Heating, Refrigerating and AirConditioning Engineers (1999) 